\title{
HOW FIRST YEAR ENGINEERING STUDENTS SELECT THEIR SPECIALIZATION AND HOW WE CAN BETTER SUPPORT THEM
}

\author{
Peter M. Ostafichuk, Carol P. Jaeger, and Agnes d'Entremont \\ University of British Columbia \\ ostafichuk@mech.ubc.ca
}

\begin{abstract}
This paper explores the student experience of discipline selection, through the perspective of students in a common first year engineering program at the University of British Columbia. It also presents and examines a number of new innovations have been introduced to the UBC curriculum to support students in this regard. In general, there is limited information in the literature about how and when engineering students decide on their specific engineering discipline. What seems to be clear though is that many, if not most, students come into common first year engineering programs with a good idea (if not a decision) of what their specialization will be. In addition, short-term factors (such as courses and program experiences) dominate decision-making rather than longterm factors (such as career potential).

The innovations we have introduced include program introduction videos, various online tools and resources, coordinated in-class presentations, program fairs, and more. Through a number of surveys to different cohorts of engineering students at UBC, several clear and encouraging trends have emerged. Most of our students report feeling well-prepared to choose their discipline by the end of first year; most students are not choosing their discipline until Term 2, after they have received information and presentations from all programs (having this time to gather information and decide is a key motivation behind a common first year); and most students report finding the new resources we are providing (online materials and tools, videos, Program Fairs, etc.) useful in their decision-making. Consistent with the literature, short-term considerations appear to dominate our students' decision-making, although there are indications that longer-term career considerations are also starting to influence their information gathering. Having opportunities to speak to current and former students in a discipline was cited by our students as the most important information source in their decision-making. Also important was information provided by programs, both within our coordinated introduction to engineering course, and through websites and other program materials.
\end{abstract}

Keywords: discipline selection, engineering programs, specialization, career planning, first year engineering

\section{INTRODUCTION}

As Ngambeki asserts [5], and supported by others [3], "if students choose an engineering [specialization] which makes the best use of their skills and engages their interest, they are more likely to not only stay, but thrive in the field of engineering which they choose". As such, it is essential that students have the necessary information, and they have properly considered it, in order to make an informed decision about the discipline of engineering they are going to enter. (Throughout this paper, "discipline" and "specialization” are used interchangeably.) Although variations exist, engineering schools tend to fall into one of two broad models: direct entry, where students join their chosen discipline directly from high-school, and common first year, where students join their chosen discipline starting in second year or later. This paper will consider the latter case, such that the school has a significant opportunity — and, arguably, obligation - to help to inform and support students through the process of discipline selection. Having said that, many of the lessons from the common first year model do translate to the direct entry model.

There is a wealth of studies in the literature about why students choose engineering as a career, as well as many studies examining what factors influence retention; however, there is comparatively little information available about the factors and decision-making process for how students choose their specialization within engineering. Although sparse, the literature does indicate that the factors that influence a student's choice of program include their interests [5],[10], socialisers (e.g. teachers, friends, family, peers) [2],[5],[9],[10], prior knowledge of the subject [6], information available on the Internet [2], their expected success in the courses of a discipline [4], alignment of their attitudes and values with those in the discipline [6], and other media sources [2]. Through a survey conducted at the University of British Columbia in 2008 (unpublished), the top factors influencing student decision-making, in order, were socialisers (most significantly former students to the program, then peers in first year, then parents), presentations by programs to the first year class, information on program web pages, program open houses, other courses, and finally program recruitment materials). In studying decision-making factors, Ngambeki found over 
$70 \%$ of specialization decisions made by engineering students related to short-term concerns (such as program rankings and class sizes), as opposed to long-term concerns (such as career aspirations) [6].

In addition to what influences the choice of specialization, several studies have examined when students choose their discipline. In one such study at a large Midwestern US university found over 30\% of students had chosen their discipline before beginning their degree, and by the end of the first semester this number had climbed to roughly 45\% [7]. Another similar study found that in middle-school, about $15 \%$ of engineers had already identified engineering as their field of study and roughly one third of these students had already identified their discipline; by high-school, an additional $80 \%$ had identified engineering and $40 \%$ had identified their discipline [6]. A study at a smaller Eastern US university found approximately 65\% of students had chosen their discipline before even looking at potential schools, and a further $15 \%$ made their choice while visiting or applying to schools (i.e. 80\% before beginning their first courses) [2]. Knowing when students choose their discipline is particularly important when developing materials creating programming to help students this process, yet there are significant differences in the above reported values, suggesting data specific to a given student population and institution is important.

Through a large curriculum renewal process in first year engineering at the University of British Columbia (UBC), several new innovations were introduced to assist students with discipline selection. These changes were informed by extensive consultation with students and other stakeholders. The focus of this paper is on surveys which were conducted to better understand the student discipline selection process as well as the effectiveness of the recent curriculum and student support changes. In particular, we wanted to know whether or not students felt they had the necessary information to make an informed choice of the preferred program, as well as when our students were making their decisions in comparison to observations from other institutions mentioned above and previous data we had. Results were compared to a similar survey conducted at UBC in 2008, and show positive outcomes; there has been a distinct change in student behaviour that suggests students are now more informed in their decision-making, and more confident in their decisions.

\section{COURSE AND INSTITUTION CONTEXT}

\subsection{Institutional Context}

At the University of British Columbia (UBC), like at many engineering schools, students complete a common first year and enter their specialization in second year. At UBC, there are 12 different engineering programs, including large traditional ones (such as civil, electrical, and mechanical), as well smaller, specialized ones (such as integrated, materials, and mining). Most students come into first year with at least a vague idea of what the traditional programs entail, but little or no idea of the specialized programs. Shortly after the end of first year classes, in mid-May, engineering students at UBC rank their program preferences and write a personal statement. The personal statement is available to view by the student's first choice program, and it contains the student's response to the prompt "Tell us why you think you are a great candidate for your top preference, or, if you feel that you need to explain an area of concern on your record, let us know what happened and why." Placements are then determined competitively for the limited number of spaces in each program based on GPA and a program's assessment of personal statements. The challenge, between when students first arrive and when they submit their program prefer rankings, is to adequately inform all students of their program options and how their personal aptitudes and interests align with these options. This is particularly important for the smaller, specialized programs that most students have not previously heard of and that rely on exposure to students in first year to generate interest.

\subsection{Previous Course Structure (Pre-2015)}

Before 2015, there were two main courses that were intended to assist students in selecting their program rankings. One course (APSC 122) was a mandatory 0credit, pass/fail seminar course that introduced the engineering disciplines and the engineering profession. In this course, a different engineering program would come in each week to give a presentation about that program and the related discipline. These presentations lasted roughly 50-minutes, and were followed by a 20 - to 30- minute presentation on various topics of professionalism and ethics. In an internal survey conducted in 2008, students did identify this course as one of the top sources of information in making their final program decision, but it scored 3.5 on a 1-5 scale, with a mean ranking of all options of 3.2. In other words, while the course ranked high compared to other things we were doing, the things we were doing were not all that good in students' eyes. A major student complaint about this course was the amount of time they were required to spend listening to "sales pitches" from the different programs, especially from programs that a student had already decided they were definitely not interested in.

Additionally, efforts were made through another course (APSC 151, Engineering Case Studies, 5-credits) to indirectly introduce different engineering disciplines through case studies; however, the cases and the course overall were broadly disliked by students [8]. Students gave feedback that the cases were often uninteresting and disjointed, and that they were unrelated to disciplines that 
a given student was interested in. Part of the original vision for the course was to showcase some of the smaller programs that otherwise did not receive significant exposure (including Mining Engineering, Materials Engineering, and Chemical and Biological Engineering). One issue with this approach is it failed to show the integrated, cross-disciplinary, and non-discrete nature of engineering practice. On the 2008 survey mentioned above, this course was ranked eighth out of nine different information sources for informing program choice (2.9 on a 1-5 scale, with mean across all options of 3.2).

\subsection{APSC 100 and 101 Courses}

Two new introduction to engineering courses were launched at UBC in 2015 [8]. The courses are taught in a flipped-classroom format, with a sequence of online, lecture, and studio components arranged in a whole-partwhole structure. The APSC 100 course (Introduction to Engineering I) is offered in first term and is taken by all 800 first year engineering students; the APSC 101 course (Introduction to Engineering II) is offered in second term and taken mainly by the 750 students entering engineering directly from high-school. Both courses are 3-credits, the size of a typical course in engineering. The courses rely heavily on elements of Team-Based Learning [11], and are supported by a host of digital resources and tools (including Articulate, Camtasia, peerScholar, iPeer, and Crowdmark).

Both courses are 13 weeks in length and have 4 contact hours per week. The cohort is divided into 4 large class sections (roughly 200 students each) and 14 design studio sections (roughly 60 students each). Each week, following mandatory online preparation, each student has two 50minute classes that bookend a single 110-minute studio.

\section{INNOVATIONS}

Extensive stakeholder consultation was conducted in 2014. This included meetings with leaders and representatives from all programs, meetings with student leaders, focus groups with students, meetings with administrative and student development staff, and several surveys. From these consultations, it was clear that the previous APSC 122 and APSC 151 courses were not working well (for the reasons outlined in Section 2.2).

In the new curriculum with APSC 100 and APSC 101, the following innovations were introduced, as outlined below.

\subsection{Program introduction videos}

For each engineering program, a 4-minute program introduction video (i.e. "teaser" video) was created. The videos were professionally produced, at a cost of approximately $\$ 2500$ each, paid as part of the first year redevelopment work and funded through a UBC Teaching and Learning Enhancement Fund (TLEF) grant. The videos were created by a local agency that specializes in integrated, creative, digital branding and storytelling. The agency met with each program to identify what was unique about that discipline, as well as what it was like to be a student in that program. The videos focused on storytelling and narrative, and were meant to pique students' interest, not to provide program particulars or statistics (especially since those would quickly become outdated). The same agency created all videos for two very important reasons: first, there was a common look and feel to all videos, meaning perceived differences between programs came from video content, not video style or production quality; and, second, smaller programs with fewer resources and smaller budgets were not disadvantaged compared to the larger programs with more resources and greater budgets.

The videos were used in APSC 100 as part of the weekly online preparation in APSC 100. One video was assigned each week. The choice of video was based on connecting the particular discipline to the content in the course at that time. (Note that Chemical Engineering and the closely related Chemical and Biological Engineering were considered together in a single video; and the Environmental Engineering program, where students come to UBC in third year, following two years at the University of Northern British Columbia, was not included.)

At the end of each video, students were given a link to complete a short, optional survey about what they saw. Survey prompts included the following (where the first three prompts were on a 5-point strongly agree to strongly disagree Likert scale, and the fourth prompt was an open text box):

- I feel I now have a clear understanding of what engineers in [program name] engineering do

- I feel I have a good understanding of what the student experiences in [program name] are

- This video helped increase my appreciation for [program name] engineering

- Do you have any questions you would like [program name] to address during their class presentation, or any feedback with comments you would like to share?

The survey responses were shared with the programs several days before an in-class visit (see Section 3.2).

\subsection{5-Minute In-class Presentation}

In the same week that a program was featured in the online video, representatives from that program came to class for a 15-minute in-class presentation. The decision of the 15-minue length came from an analysis of student feedback (survey and focus group) in terms of which elements in the previous 50-minute presentations in APSC 
122 (see Section 2.2) were best-suited to in-class presentation. Extensive discussion was required with program representatives before they agreed to the 15minute length. Although they were willing to concede that 50-minutes was too long, they were reluctant to accept anything less than about 25- or 30-minutes. They were eventually persuaded to accept 15-minutes by the argument that the online videos were more effectively capturing about 10 to 15 minutes of what was previously presented in person, and that additional opportunities to interact with and influence students through other activities (see below) would make up for the apparent shortfall.

The in-class presentations were done throughout Term 1 in APSC 100. Specifically, they occurred at the end of the second large class each week (i.e. in a lecture theatre with approximately 200 students). Programs were asked to refer to and build off of what students saw in the introduction videos, but to avoid repeating content. They were reminded to focus on both short-term student experiences and long-term career opportunities (acknowledging the decision-making factors typically used by students [6]). Lastly, they were informed of what was happening in the course content at the time and encouraged to try to connect to and leverage that in their presentations. Perhaps the most successful example of this integration was in a course module on decision-making involving a large hydroelectric dam. A representative from Geological Engineering was able to come in and take over some of the formal course material on stakeholder engagement and decision-making hydroelectric dams based on their consulting experience doing just that. They then transitioned to the 15-minute presentation for Geological Engineering as a discipline and program while weaving in the formal course content and anecdotes they had just discussed.

Programs were given the feedback from the survey that accompanied the online videos (see Section 3.1). Notably, this allowed programs to tailor their presentations and messages based on feedback and common questions raised in the survey. Each program handled the presentations different. Most used a faculty presenter, sometimes the head, and many had a student representative co-present. Some programs relied on student presenters, with faculty present to answer questions, if necessary.

\subsection{Online Resources}

In addition to the 4-minute introduction videos, we curated a set of online resources for students about the different engineering disciplines. This included a summary of each program on a wiki page to address the most common student questions. These included a description of the discipline, especially what makes it distinct from other engineering disciplines; a summary of the core course content and typical course load; information on the job market and industries; and information on the student experience. Some programs have also begun using student ambassadors that blog their experiences in that program on a roughly weekly basis.

We heard anecdotally-and, on occasion observed during in-class presentations by the programsmisinformation circulating regarding salary statistics and entrance requirements. In response to the salary misinformation, we directed students to the most recent salary and compensation information reported by APEGBC [1]. (We prefaced this with a warning that salary should not be the only factor considered, if considered at all, in selecting a discipline.)

Students at UBC competitively apply to their programs, and their GPA and their personal statement are important factors in determining which program they are accepted to. The personal statement is only read by their first choice program, but if the student's GPA is highly noncompetitive, the likelihood that they would be accepted to a program, even with a strong personal statement, is low. For this reason, it is beneficial for students to know which programs their GPA would be considered competitive for such that they use their personal statement wisely. For this reason, we began releasing the historical GPA data of all first choice applicants by program. To avoid having students read more into the data than was present, we gave four-year rolling averages of median GPA, $20^{\text {th }}$ percentile GPA (i.e. $80 \%$ of first-choice applicants admitted had a higher GPA), and $5^{\text {th }}$ percentile GPA.

\subsection{Open Houses and Program Fair}

Programs have been offering open houses to tour their facilities and promote their programs for years. With APSC 100 and 101 we moved to coordinate this more with three objectives in mind. First, where possible, we tried to synchronize an open house for a program to follow the week after online videos (Section 3.1) and in-class presentations (Section 3.2). Second, we tried to minimize overlap between open houses to avoid unintentional but unfair competition between larger programs (with more resources and attractions to draw students) and smaller programs. Students are also strongly encouraged to attend a faculty-wide open house that takes place in late fall and has all programs represented. Third, we work with programs to advertise open houses in APSC 100 and 101 classes, and online.

In addition, we introduced what we have called a "program fair" in Term 2. This one-day optional event is structured a bit like a job fair. It is specific to first year students, and is geared towards helping them get information to make informed choices. Student, faculty, and staff representatives from each program are present to answer questions. We felt it was particularly important to have students in the programs present, given the importance of this particular group of socialisers in discipline decision-making (see Section 1). To avoid 
competition and biases, it is clearly communicated to programs that the goal of this event is specifically to provide information, not for promotion or recruitment.

\subsection{Curriculum Content}

It is clearly communicated to students in APSC 100 that an understanding of the different engineering disciplines is part of the curriculum. Midterm and final exams questions are included, such as ones that require students to describe the key distinguishing characteristics of a discipline, or to compare and contrast two or more related disciplines. In APSC 101, several writing exercises are included in which students identify their interests and aptitudes, and then identify programs that strongly relate to those with a description of why.

\subsection{Engineering Program Questionnaire Tool}

Our most recent innovation is an interactive, online discipline selection tool, inspired by a similar tool at the University of Waterloo (http://www.engineering. uwaterloo.ca/undergraduate/quiz/) and piloted in January this year. The tool is meant to help students quickly explore which engineering programs at UBC might be a good fit for their interests and working styles. To create the tool, a survey based on the work at Waterloo was sent to recent graduates and senior students in UBC Engineering. Based on 858 valid responses, we looked for indicators that respondents were either satisfied or very satisfied with their program choice ( $n=642$ ), and otherwise excluded their responses. A classification and regression tree analysis (CART) [12] was performed on the data. CART is a binary decision tree that can accept variables with more than two values, and only uses the variables (and values) that are the best predictors of the dependent variable (in this case, engineering discipline). Six factors (out of 16) were found to be the best predictors of a (satisfied) survey respondent's discipline: interest in technologies related to the discipline, degree of positive impact on society, tangibility of project outcomes, type of analysis artifacts, type of team, and work environment. Through the CART analysis, we identified the four programs most strongly associated with each leaf on the decision tree (following from a particular set of selections from the six factors), and created an interactive online tool.

The online program questionnaire tool was created using the Articulate Storyline 2 software. The resulting tool was interactive and standalone, although our students accessed it through our learning management system (Blackboard). The tool asks for a response to the six key factors described above, presented in random order and using animated text and graphics (an example screen is shown in Fig. 1). Most people complete the questionnaire in less than one minute.

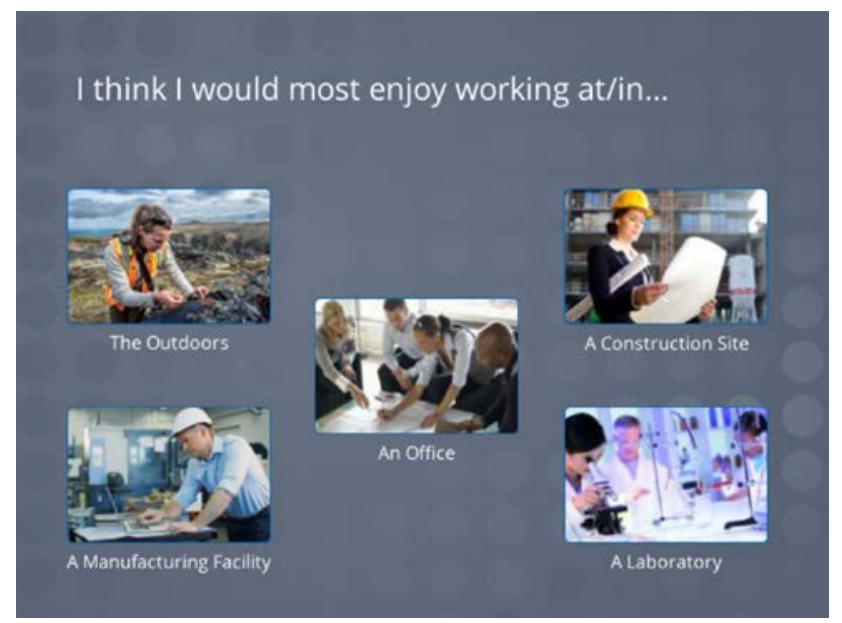

Fig. 1. Sample screenshot from questionnaire tool

The tool then provides a summary screen with the four disciplines most strongly connected to the responses, based on the CART analysis. A short summary description is provided for each discipline (see Fig. 2), and upon clicking a discipline's box, students are taken to the full wiki page for that discipline, as described in Section 3.3.

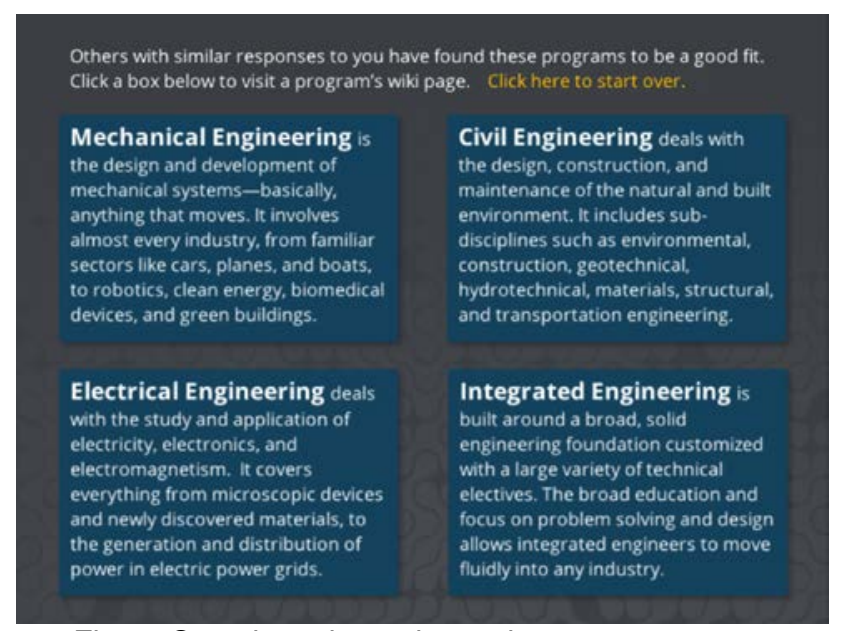

Fig. 2. Questionnaire tool sample summary screen

\section{SURVEY ANALYSIS}

\subsection{Preparation in Decision-Making}

In the 2008 survey conducted at UBC, 48\% of students reported being only "somewhat prepared" and $16 \%$ reported being "not at all prepared" to select their discipline at the end of first year. In the 2015 survey, these numbers dropped to $28 \%$ and $2 \%$, respectively-in other words, students report feeling much better prepared to choose their programs now.

In a related question stated "One of the goals of APSC 100 was to introduce you to the various disciplines and help you develop a basic understand of what each discipline 
involves. How successful was the course in this regard?” The responses, on a four-point scale, are shown in Fig. 3 and indicate that roughly two-thirds of students feel the course is successful to very successful in this goal.

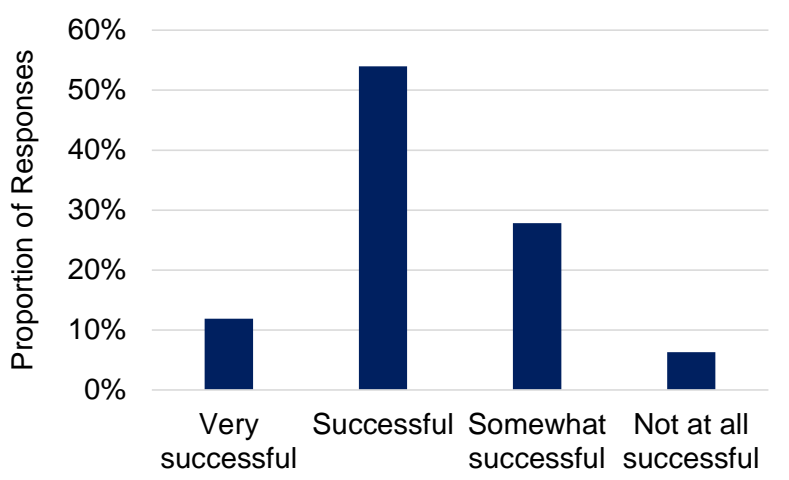

Fig. 3. Success of APSC 100 in introducing the disciplines

Taken together, these results indicate students are better supported and better prepared to select their discipline as a result of the recent changes. With additional refinements this year based on suggestions from the 2015-16 cohort, we are anticipating a further improvement in these numbers.

\subsection{Timing of Decisions}

A summary of when students selected their engineering discipline is provided in Table 1 . The UBC 2015 data represents responses from 126 students from the 2015-16 cohort (about $15 \%$ of first year students that year) to an optional survey conducted in the fall of 2016. Students were asked "when did you decide what your first choice program would be?” This is compared against 368 responses from a similar survey in 2008 (about $50 \%$ of that cohort). Also shown are the data from three separate studies mentioned in Section 1. Data for the 2016-17 academic year at UBC will not be available until later this summer.

Table 1: Timing of discipline selection

\begin{tabular}{|c|c|c|c|c|c|}
\hline \multirow{3}{*}{ Time } & \multicolumn{5}{|c|}{ Proportion Selecting Discipline } \\
\hline & \multirow{2}{*}{$\begin{array}{l}\text { UBC } \\
2015\end{array}$} & \multirow{2}{*}{$\begin{array}{l}\text { UBC } \\
2008\end{array}$} & \multicolumn{3}{|c|}{ Others } \\
\hline & & & [7] & [6] & {$[2]$} \\
\hline Summer prior & $24 \%$ & $34 \%$ & $33 \%$ & $45 \%$ & $85 \%$ \\
\hline Term 1 & $18 \%$ & $11 \%$ & $13 \%$ & $45 \%$ & \\
\hline Term 2 & $36 \%$ & $26 \%$ & & & $15 \%$ \\
\hline After Term 2 & $22 \%$ & $30 \%$ & & & \\
\hline
\end{tabular}

In general, we view the results as very promising. One key benefit of a common first year is that students get a chance to learn more about the engineering disciplines before making a choice as to which one they wish to pursue. Our smaller programs, in particular, like to see students explore their options and not commit to a discipline until later in first year. The majority of our students (58\%) are deciding on their program in Term 2 or later, after all disciplines have had an opportunity to present to them in Term 1. Compared to 2008, we have more students choosing to their program after they arrive, and fewer students delaying their choice until after Term 2.

In a related question on the same survey, students were asked if they had a first choice program in mind before coming to UBC, to which $40 \%$ indicated feeling "certain" and $30 \%$ indicated "having a good idea." Although this reflects a self-reported perception upon reflection rather than the time of an actual decision, these numbers are more reflective of those reported in other studies [2],[6],[7]. Of the $70 \%$ of students who reported having at least a good idea of their first choice program, $61 \%$ (i.e. $43 \%$ overall) indicated eventually ranking this same program as their first choice. In conjunction with the data in Table 1, it is also encouraging as it suggests that even if most students come in with a strong idea of the discipline they are most interested in, they also keep an open mind during first year and do not commit to their final choice until they have more complete information.

\subsection{Decision-making Information Sources}

In the survey of the 2015-16 cohort, students were asked to rate how useful each of the various supporting elements and activities was towards refining and ranking their program choices. The results are summarized in Fig. 4 below, ranked from overall most useful on the top to least on the bottom. All items were rated "somewhat useful" or better by least $80 \%$ of respondents. (Note: the engineering program online questionnaire was not available to the 2015-16 cohort, but survey data will be collected this summer for the most recent cohort.)

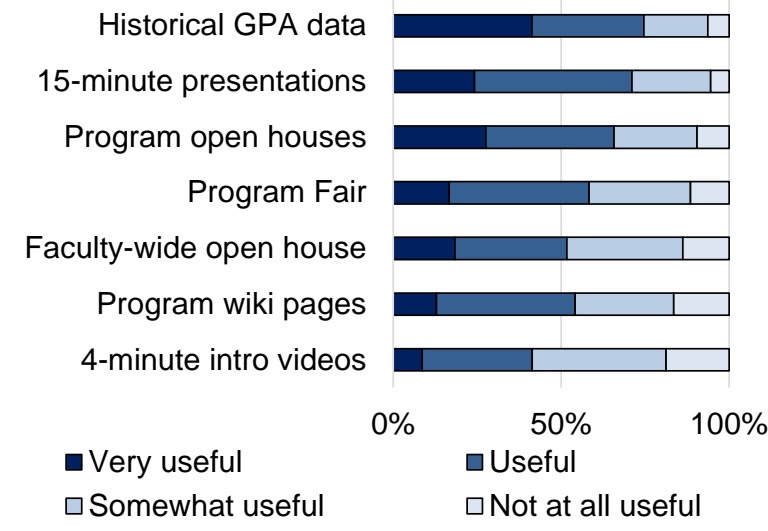

Fig. 4. Student rating of utility towards program ranking

In a related question, students were asked to identify the top three factors used in ranking their program choices. Using a rating of 3 for top choice, 2 for second, and 1 for third, the relative ranking of the various information 
sources is shown in Fig. 5. Current and former students in the program are identified as most commonly, which makes sense given Ngambeki's findings that $70 \%$ of students make their decision based on short-term considerations (e.g. what will my courses and program look like) rather than longer-term career goals [6]. It is also interesting that of the socialisers, parents, relatives, and peers are less influential than current and former students.

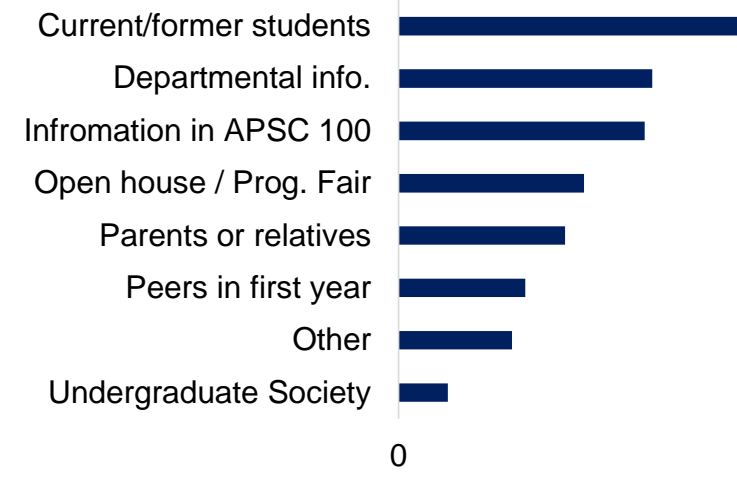

Fig. 5. Relative ranking of information sources

The relatively low rating of the 4-minute program introduction videos (i.e "teaser" videos) in Fig. 4 were not of concern given the purpose of the videos was to raise awareness of the different programs and pique interest for the in-class presentations, and not to provide an information-dense resource to be used in final program selection and ranking. An assessment of the effectiveness of the videos towards this stated goal is provided next.

\subsection{Online Video Exit Surveys}

Regarding the online videos (Section 3.1), approximately 250 students (30\% of the cohort) replied to each end-of-video survey, even though the surveys were optional. The results to the first three prompts, on a "strongly agree" to "strongly disagree" Likert scale, are shown in Fig. 6 (see Section 3.1 for full survey prompts). These results are encouraging in that approximately 80\% of students on average report a greater appreciation for a discipline after watching the video, and a similar proportion report an understanding of both the discipline and the student experiences in the program.

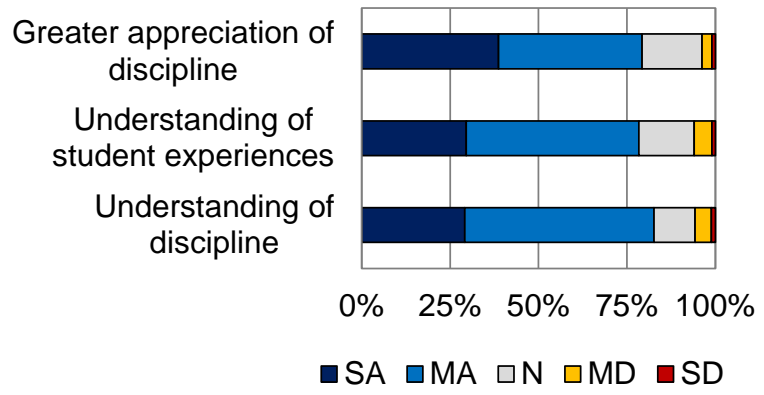

Fig. 6. Summary of post-video survey data
Equally encouraging, there was no statistical difference observed between the smaller, less well known programs, and the large programs in any of the three criteria. In other words, prior knowledge of a discipline did not appear to significantly impact a student's appreciation or understanding from the video.

\subsection{Program Fair Survey}

Terms of the Program Fair, an optional survey was released to the current (2016-17) cohort shortly after the event. In total 106 students (roughly 15\% of the cohort) responded to the survey. Of the respondents, $60 \%$ indicated they attended the Program Fair, and those who did not cited a variety of reasons why: too busy (36\%), already had all the information needed (21\%), did not know about it (13\%), did not see the value (10\%), and forgot (8\%). Of attendees, $56 \%$ found it effective or very effective, 39\% found it somewhat effective, and 5\% found it not at all effective. The most common information sought at the event included

- $\quad$ The student experience within programs (67\%)

- $\quad$ Career options available (67\%)

- Admission requirements (55\%)

- Options within programs (53\%)

- Course offerings (50\%)

- All other (15\%)

This is again consistent with Ngambeki's findings that 70\% of students make their decision based on short-term considerations rather than longer-term career goals [6]. Still, even though the majority of factors were short-term in nature, it is encouraging to see two-thirds of students identifying obtaining career option information as a motivator for attending the Program Fair.

\subsection{Other factors}

Several interesting observations from the surveys but not captured above include the following:

- When considering GPA, and specifically the historical GPA data summary by program provided to students, $21 \%$ of survey respondents indicated that seeing the GPA data encouraged them to change their first choice program to one that was more competitive (had higher entrance requirements). Conversely, $14 \%$ of respondents were worried about their chances of being placed in a program after seeing the GPA data, and as a result they changed their first choice program to one that was less competitive. (From 2015-16 cohort survey.)

- After first year, 52\% of students on average replied that their understanding of each engineering discipline changed "moderately" or "significantly," while the remainder (48\%) reported "little” or "no" 
change. The responses were only slightly different for the small programs (55\% moderate or significant change, $45 \%$ little or no change). (From 2015-16 cohort survey.)

- At the time of completing the online program questionnaire, students from the 2016-17 cohort reported their results on a short survey. Over $80 \%$ of students reported that the program they were most interested in appeared in the list of four candidate programs to consider in the tool, $12 \%$ reported that the program they are most interested in does not appear, and $8 \%$ were unsure or undecided.

\section{CONCLUSIONS}

Several innovations have been introduced to the UBC first year engineering curriculum to support students in selecting their discipline for second year. These innovations include program introduction videos, online tools and resources, coordinated in-class presentations, program fairs, and more. As a result of these changes, more students now report feeling well-prepared to choose their discipline by the end of first year, and more students are choosing their discipline at a time that suggests they are considering the information provided and weighing their options. Short-term considerations appear to dominate our students' decision-making, although there are indications that longer-term career considerations are also starting to influence their information gathering. Students cited access to historical GPA admission information, in-class presentations, and open houses as the most impactful innovations on their discipline selection process. Students identified conversations with current or former students in a discipline as the single most important factor in informing their decision, suggesting it is important to give opportunities and experiences where this can happen.

\section{Acknowledgments}

We wish to thank the University of British Columbia Teaching and Learning Enhancement Fund (TLEF) for funding the work to redevelop our first year engineering curriculum. We also wish to thank Ryan Pyear and the University of Waterloo for sharing the data and methodology used in creating their online engineering program questionnaire (http://www.engineering. uwaterloo.ca/undergraduate/quiz/)

\section{References}

[1] APEGBC, 2016 Report on Members' Compensation and Benefits. [Online]. Available: https://www.apeg.bc.ca/Careers/Compensation-Survey
[2] M.-I. Carnasciali, A.E. Thompson, T.J. Thomas, "Factors influencing students' choice of engineering major," in Proc. of ASEE 2013, 35 pp., Atlanta, 2013.

[3] M.A. Hutchison, D.K. Follman, and G.M. Bodner, "Shaping the Self-Efficacy Beliefs of First-Year Engineering Students: What is the Role We Play?" in Proc. of ASEE 2005, Portland, 2005.

[4] J.B. Main, K.J. Mumford, and M.W. Ohland, "Examining the Influence of Engineering Students' Course Grades on Major Choice and Major Switching Behavior," International Journal of Engineering Education Vol. 31, No. 6(A), pp. 1468-1475, 2015.

[5] I.B. Ngambeki, O. Dalrymple, and D. Evangelou, "Decision-making in First-Year Engineering: Exploring how Students Decide About Future Studies and Career Pathways,” in Proc. of ASEE 2008, 12 pp., Pittsburgh, 2008.

[6] I.B. Ngambeki, "Finding a Home in Engineering: Examining Students' Choice of Engineering Discipline," Ph.D. dissertation, Purdue University, 143 pp., 2012.

[7] J.S. Noonan, W.C. Oakes, and P.K. Imbrie, "First-Year Engineering Students' Choice of a Major: When it is Made and What Influences It,” in Proc. of ASEE 2006 Illinois-Indiana and North Central Joint Section Conference, 11 pp., Fort Wayne, 2006.

[8] P.M. Ostafichuk, C.P. Jaeger, J. Nakane, S. Nesbit, N. Ellis, J. Sibley, "Redesigning the UBC First Year Introduction to Engineering: Successes and Challenges," in Proc. of CEEA 2016, 8 pp., Halifax, 2016.

[9] B. Reed and J. Case, "Factors influencing learners' choice of Mechanical Engineering as a career," African Journal of Research in Mathematics, Science and Technology Education, 7, pp. 73-83, 2003.

[10] D.C. Shallcross, "Factors Influencing the Selection of Chemical Engineering as a Career," Chemical Engineering Education, pp. 263-81, Fall 2003.

[11] J.E. Sibley, and P.M. Ostafichuk, Getting Started with Team-Based Learning. Sterling, Virginia: Stylus, 2014, 256 pp. \{ISBN: 978-1620361962\}

[12] R. Timofeev, "Classification and Regression Trees (CART): Theory and Applications," Masters Thesis, Humboldt University, Berlin, 40 pp., 2004. 